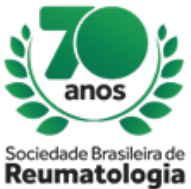

CENTRO DE EVENTOS DO CEARÁ O4 A 07 DE SETEMBRO

\title{
SACROILITIS IN A PATIENT WITH SARCOIDOSIS: CASE REPORT
}

Anauá Fernanda dos Santos Cavalcante (Hospital Universitário Evangélico Mackenzie, Curitiba, PR, Brasil), Jhésyca Castaman Stédile (Hospital Universitário Evangélico Mackenzie, Curitiba, PR, Brasil), Thiago Alberto G. Santos (Hospital Universitário Evangélico Mackenzie, Curitiba, PR, Brasil), Thelma Laroke Skare (Hospital Universitário Evangélico Mackenzie, Curitiba, PR, Brasil), Deborah Cristyne Colombo Ito (Hospital Universitário Evangelico Mackenzie, Curitiba, PR, Brasil), Juliana Delfino (Hospital Universitário Evangélico Mackenzie, Curitiba, PR, Brasil)

\section{BACKGROUND}

Sarcoidosis is a systemic granulomatous disease of unknown etiology that can affect any organ bur most commonly lung and intrathoracic lymph nodes. Musculosketal involvement is considered rare and is more common in afrodescendant males. It is commonly connected with disease in the eye and lungs. There are rare descriptions of sacroiliitis in the literature, mainly unilateral. While the prevalence of sacroiliitis in the general population is estimated in $1.9 \%$, in sarcoidosis this prevalence raises to $6.6 \%$ suggesting some association between these two entities.

Objective: To describe a case of sarcoidosis in a patient with bilateral sacroiliitis.

\section{CASE REPORT}

E.F.S. male, 50 years old, Afrodescendant, seeks medical attention for pain and edema in proximal interphalangeal joints, knees and feet bilaterally, migratory, of two months duration. He reported sporadic pain in the lumbar region, intermittent fever, dry cough, a generalized erythematous cutaneous rash, and weight loss of $10 \mathrm{~kg}$ in this period. Physical examination showed diffuse cutaneous erythematous rash, more evident in the anterior thorax and upper limbs and arthritis in proximal interphalangeal joints bilaterally. Hand's $X$ rays showed only reduction of articular space in the interphalangeal joints. Chest tomography revealed micronodular septal thickening with perilymphatic distribution and enlarged hilar lymph nodes, as well as in mediastinum, and lower cervical region. Magnetic resonance revealed bilateral sacroiliitis. A transbronchial biopsy was performed and a biopsy showed granulomatous chronic inflammatory process, without necrosis. The diagnosis of sarcoidosis with pulmonary and joint involvement was established and the patient was started on prednisone $20 \mathrm{mg} /$ day and methotrexate (up to $25 \mathrm{mg} /$ week). In the last consultation the patient still had some mild articular symptoms; hydroxychloroquine was added.

\section{CONCLUSION}

Sarcoidosis should be included in the differential diagnosis of sacroiliitis.

References:

1 Nessrine A, Abourazzak FZ, Harzy T. Músculo-esquelético na sarcoidose. J Bras Pneumol 2014; v40:17582.

2 Figuero LSB, Temino ARZ, Castrillon JL. Sarcoidosis and sacroiliitis, a case report. Rheumatol Int 2012; v32: $2949-50$. 